\title{
PRESTASI BELAJAR MAHASISWA FUNGSIONARIS UKM KSR PMI UNIT UNIVERSITAS NEGERI MALANG
}

\author{
Imam Gunawan, Dwi Meinita Sari, Sisco Agustian, Shofiyatul Marwiyah, Naufal Danar \\ Bagaskara, Maghfirotun Sa'diyyah, Binti Nafi'atus Safa'ah, Lailatun Nikmatasari, Annisa' \\ Hayyu Fi'isyatirrodhiyah, Titik Istirohah, Ike Fuji Lely, Dinda Putri Ratnasari, M. Adib \\ Wijaya, Dwi Retno Y, Ahmad Ridwan, Dewi Khusnul Chotimah, Qonitatul Labibah, Eva \\ Trisnawati, Afiatur Rofika Sari, Dewi Ghusti D, Elma Wati Purnama Sari, Isyatul Karimah, \\ Abdul Hakim, Endang Amaliana Fatma Yuantika, Nila Ratnawati, Dwi Ayu Atika Sari \\ Universitas Negeri Malang, Jalan Semarang 5 Malang 65145 \\ Email: imam.gunawan.fip@um.ac.id
}

\begin{abstract}
The purpose of this research is to describe the students achievement of the Volunteer Corps of Indonesian Red Cross Unit State University of Malang (UKM KSR PMI Unit Universitas Negeri Malang). This research uses quantitative approach. Data collection techniques are documentation of Grade Point Average (GPA). The sample of this research is the student of functionary UKM KSR PMI Unit Universitas Negeri Malang. The research data is the GPA of functionary UKM KSR PMI Unit Universitas Negeri Malang. Data analysis is with descriptive statistics, ie by count the mean and standard deviation. Further data is displayed in the frequency description by referring to the stanfive formula, as a reference for defining categories. The result of the research shows that the average GPA of functionary UKM KSR PMI Unit Universitas Negeri Malang are 3.52 is included in the predicate cum laude.
\end{abstract}

Keywords: learning achievement, student functionaries, voluntary corps

\begin{abstract}
Abstrak: Tujuan penelitian ini adalah untuk mendeskripsikan prestasi belajar mahasiswa fungsionaris Unit Kegiatan Mahasiswa Korps Sukarela Palang Merah Indonesia Unit Universitas Negeri Malang (UKM KSR PMI Unit Universitas Negeri Malang). Penelitian ini menggunakan pendekatan kuantitatif. Teknik pengumpulan data adalah dokumentasi indeks prestasi mahasiswa. Sampel penelitian adalah mahasiswa pengurus UKM KSR PMI Unit Universitas Negeri Malang. Data penelitian adalah indeks prestasi mahasiswa pengurus UKM KSR PMI Unit Universitas Negeri Malang. Analisis data adalah dengan statistika deskriptif, yakni dengan menghitung rerata dan deviasi standar. Selanjutnya data ditampilkan dalam deskripsi frekuensi dengan mengacu pada rumus stanfive, sebagai acuan menentukan kategori. Hasil penelitian menunjukkan rerata indeks prestasi mahasiswa fungsionaris UKM KSR PMI Unit Universitas Negeri Malang sebesar 3,52 termasuk dalam predikat Dengan Pujian.
\end{abstract}

Kata kunci: prestasi belajar, mahasiswa fungsionaris, korps sukarela

Mahasiswa merupakan peserta didik di perguruan tinggi yang berusaha mengembangkan potensi diri melalui proses pembelajaran di perguruan tinggi. Mahasiswa merupakan insan generasi penerus bangsa. Undang-undang Nomor 12 Tahun 2012 tentang Pendidikan Tinggi menegaskan mahasiswa sebagai anggota sivitas akademika diposisikan sebagai insan dewasa yang memiliki kesadaran sendiri dalam mengembangkan potensi diri di perguruan tinggi untuk menjadi intelektual, ilmuwan, prak- tisi, dan/atau profesional. Oleh sebab itu, menjadi kewajiban perguruan tinggi menyiapkan para mahasiswanya untuk dapat meneruskan estafet generasi bangsa. Penyiapan tersebut harus memadukan antara aspek akademik dan nonakademik, agar pengembangan kompetensi diri mahasiswa menjadi utuh dan komprehensif. Kompetensi mahasiswa ditentukan oleh keseimbangan mahasiswa dalam mengikuti kegiatan akademik dan nonakademik di perguruan tinggi. Kegiatan akademik dan no- 
nakademik dikembangkan agar mahasiswa kelak dapat menjadi anggota masyarakat yang memiliki kemampuan akademis dan/atau profesional yang dapat menerapkan, mengembangkan, dan menyebarluaskan ilmu pengetahuan, teknologi, dan/ atau kesenian serta memperkaya budaya nasional (Gunawan, 2009).

Kegiatan akademik meliputi kuliah, seminar, diskusi, praktikum, tugas mandiri, dan pengabdian masyarakat (Triana, 2011). Mahasiswa sebagai insan akademik memiliki tradisi ilmiah dengan mengembangkan budaya akademik. Undangundang Nomor 12 Tahun 2012 tentang Pendidikan Tinggi menegaskan budaya akademik merupakan seluruh sistem nilai, gagasan, norma, tindakan, dan karya yang bersumber dari ilmu pengetahuan dan teknologi sesuai dengan asas pendidikan tinggi. Mahasiswa mengembangkan bakat, minat, dan kemampuan dirinya melalui kegiatan kokurikuler dan ekstrakurikuler sebagai bagian dari proses pendidikan. Tingkat keberhasilan prestasi belajar yang dicapai mahasiswa dari semua kegiatan akademik yang diikuti dalam jangka waktu tertentu yang dinyatakan dalam bentuk bilangan disebut Indeks Prestasi (Haryono, dkk., 2013).

Kegiatan nonakademik adalah berbagai kegiatan yang dilakukan dalam rangka kesempatan kepada mahasiswa untuk dapat mengembangkan potensi, minat, bakat, dan hobi yang dimilikinya yang dilakukan di luar jam kuliah (Kartika, 2016; Mulyono, 2008). Prestasi nonakademik adalah suatu prestasi yang tidak dapat diukur dan dinilai menggunakan angka, misalnya bidang olah raga atau kesenian (Kartika, 2016). Wadah mahasiswa dalam mengembangkan kegiatan nonakademik adalah organisasi kemahasiswaan (ormawa). Ormawa dimaksudkan sebagai suatu wahana dan sarana pengembangan diri mahasiswa ke arah perluasan wawasan dan peningkatan kecendikiawanan berserta integritas kepribadian (Universitas Negeri Malang, 2016).

Mahasiswa yang tergabung dalam ormawa lazim disebut aktivis. Namun demikian, yang harus diketahui secara terminologi, ada perbedaan antara aktivis, organisatoris, dan fungsionaris. Aktivis adalah orang yang giat bekerja untuk kepentingan suatu organisasi politik atau organisasi massa lain (Pusat Bahasa, 2008). Aktivis mengabdikan tenaga dan pikirannya, bahkan seringkali mengorbankan harta bendanya untuk mewujudkan cita-cita organisasi (Badan Pengembangan dan Pembinaan Bahasa, 2017). Activist is a person who campaigns to bring about political or social change (Oxford Dictionaries, 2017a). Aktivis ialah sebagai orang yang terlibat dalam mengorganisasi perubahan politik atau sosial. Organisatoris adalah bersifat ahli dalam mengorganisasikan (Pusat Bahasa, 2008). Organizer is a person who arranges an event or activity; a thing used for organizing (Oxford Dictionaries, 2017b). Fungsionaris ialah merupakan orang yang beraktivitas atau menjalankan suatu organisasi; pejabat; anggota pengurus; yang menduduki fungsi (Pusat Bahasa, 2008). Functionary is one who serves in a certain function (Merriam Webster, 2017). Functionary is a person who has official duties, especially in a government or political party (Dictionary Cambridge, 2017).

Berdasarkan definisi tersebut, disimpulkan bahwa aktivis adalah pegiat yang berupaya mengarahkan masyarakat atau anggota organisasi untuk berubah menuju tatatan masyarakat atau organisasi yang lebih baik; organisatoris merupakan seorang pemimpin pengembang sistem dan budaya organisasi; dan fungsionaris adalah seorang pengurus, pengelola organisasi. Fungsionaris tentu organisatoris dan aktivis; organisatoris belum tentu fungsionaris, tetapi tentu orang aktivis; dan aktivis belum tentu organisatoris dan fungsionaris. Persamaan dari ketiganya adalah sama-sama mengabdikan dirinya untuk kemajuan organisasi dengan berbagai peran dan tugasnya masingmasing. Menjadi tantangan sendiri bagi mahasiswa fungsionaris dalam ormawa untuk dapat mengatur waktunya agar seimbang antara kegiatan akademik (kuliah) dengan kegiatan nonakademik di ormawa. Mahasiswa fungsionaris ormawa selain disibukkan dengan kegiatan kuliah, ia juga disibukkan dengan kegiatan mengurus organisasi, seperti rapat, menyelenggarakan program kerja, atau koordinasi dengan organisari lain, baik di dalam atau pun di luar kampus.

Bersatunya peran mahasiswa sebagai seorang pelajar akademis dan aktivis dalam diri mahasiswa, tentu menjadi sebuah tanggung jawab yang besar agar kedua peran tersebut dapat berjalan dengan baik (Sule, 2016). Mahasiswa aktivis harus mengorbankan sebagian dari pikiran, tenaga, 
materi, dan waktu untuk kegiatan organisasi yang diikutinya (Sule, 2016). Oleh karena itu, ini akan berpengaruh pada prestasi belajar mahasiswa aktivis (Sule, 2016). Mahasiswa fungsionaris dituntut mampu menerapkan strategi belajar untuk menyeimbangkan antara kegiatan organisasi dan akademik (Caesari, dkk., 2013). Tuntutan tersebut selaras dengan pendapat Fry, dkk., (2009) yang menyatakan bahwa strategi belajar bukan hanya murni terbentuk dari karakteristik individual seseorang saja, namun juga merupakan suatu respons terhadap keadaan lingkungan sekitarnya. Tujuan penelitian ini adalah untuk mendeskripsikan prestasi belajar mahasiswa fungsionaris Unit Kegiatan Mahasiswa Korps Sukarela Palang Merah Indonesia Unit Universitas Negeri Malang (UKM KSR PMI Unit Universitas Negeri Malang).

\section{METODE}

Metode penelitian dengan menggunakan pendekatan penelitian kuantitatif. Teknik pengumpulan data penelitian adalah dengan dokumentasi, yaitu dokumen Kartu Hasil Studi (KHS) mahasiswa. Populasi penelitian ini adalah mahasiswa pengurus UKM KSR PMI Unit Universitas Negeri Malang. Data penelitian adalah indeks prestasi mahasiswa pengurus UKM KSR PMI Unit Universitas Negeri Malang, yakni dua periode kepengurusan. Setiap satu periode kepengurusan, mahasiswa yang menjadi pengurus sebanyak 30 orang mahasiswa, sehingga mahasiswa yang menjadi populasi penelitian ini sebanyak 60 orang mahasiswa. Data indeks prestasi mahasiswa adalah selama dua tahun ajaran (empat semester, setiap tahun ajaran yaitu semester gasal dan semester genap). Analisis data penelitian yang digunakan adalah dengan statistika deskriptif (Gunawan, 2016), yakni dengan mencari rerata $(\overline{\mathrm{X}})$ dan deviasi standar (DS). Selanjutnya data ditampilkan dalam deskripsi frekuensi dengan mengacu pada rumus stanfive, sebagai acuan menentukan kategori. Rumus stanfive seperti ditampilkan pada Tabel 1.

\section{HASIL}

Data hasil belajar mahasiswa fungsionaris dalam penelitian ini adalah indeks prestasi mahasiswa pengurus UKM KSR PMI Unit Universitas Negeri Malang, yakni dua periode kepengurusan. Data indeks prestasi tersebut seperti ditampilkan pada Tabel 2. Berdasarkan Tabel 2 diketahui: rerata indeks prestasi mahasiswa sebesar 3,52; dan deviasi standar indeks prestasi mahasiswa sebesar 0,26. Berdasarkan data pada Tabel 2, selanjutnya dideskripsikan dengan rumus stanfive (Tabel 1). Deskripsi frekuensi indeks prestasi mahasiswa fungsionaris UKM KSR PMI Unit Universitas Negeri Malang seperti ditampilkan pada Tabel 3.

Berdasarkan Tabel 3 diketahui mahasiswa yang memperoleh indeks prestasi: (1) > 3,91 dengan kategori sangat baik sebanyak 1 orang mahasiswa (1,16\%); (2) 3,65 s.d. 3,91 dengan kategori baik sebanyak 29 orang mahasiswa (33,72\%); 3,39 s.d. 3,65 dengan kategori cukup baik sebanyak 33 orang mahasiswa $(38,37 \%) ; 3,13$ s.d. 3,39 dengan kategori kurang baik sebanyak 16 orang mahasiswa $(18,60 \%)$; dan $<3,13$ dengan kategori tidak baik sebanyak 7 orang mahasiswa (8,14\%). Jika mengacu pada Pedoman Akademik Universitas Negeri Malang (2015), maka rerata indeks prestasi mahasiswa fungsionaris UKM KSR PMI Unit Universitas Negeri Malang sebesar 3,52 termasuk dalam predikat Dengan Pujian.

Capaian hasil selain akademik fungsionaris, juga diperoleh capaian prestasi organisasi. Capaian prestasi organisasi UKM KSR PMI Unit Universitas Negeri Malang tersebut diantaranya: (1) didanainya Program Hibah Bina Desa (PHBD) Kementerian Riset, Teknologi, dan Pendidikan Tinggi Tahun Anggaran 2015, dengan judul Pemanfaatan Radio Pancar Ulang / Repeater untuk Optimalisasi Komunikasi SIBAT (Siaga Bencana Berbasis Masyarakat) di Daerah Rawan Bencana Gunung Kelud; (2) National Voluntary Red Cross Competition (NVRCC) Tahun 2016 Universitas Negeri Semarang, meraih Juara Grade B; (3) Temu Karya Relawan KSR PMI Unit Perguruan Tinggi Se-Kota Malang Terbuka Tahun 2016 PMI Cabang Kota Malang, meraih Juara 2 Desain Leaflet, Juara 2 Lukis Kaos, Juara 3 Lukis Kaos, dan Juara 2 Pertolongan Pertama; (4) Invitasi Keterampilan Relawan Antar KSR PMI Se-Jawa Tahun 2017 Universitas Negeri Yogyakarta, meraih Juara 2 Lomba Pertolongan Pertama dan Juara 2 Lomba Karya tulis ilmiah; dan (5) Ormawa of the Year 2017 Universitas Negeri Malang, meraih Juara 2 Kategori Lomba Website; Juara 3 Kategori Lomba Kebersi- 
Tabel 1 Rumus Stanfive

\begin{tabular}{cll}
\hline No & \multicolumn{1}{c}{ Formula Rumus } & \multicolumn{1}{c}{ Kategori } \\
\hline 1 & $(\overline{\mathrm{X}}+1,5 \mathrm{DS})<\mathrm{X}$ & Sangat baik \\
2 & $(\overline{\mathrm{X}}+0,5 \mathrm{DS})<\mathrm{X}<(\overline{\mathrm{X}}+1,5 \mathrm{DS})$ & Baik \\
3 & $(\overline{\mathrm{X}}-0,5 \mathrm{DS})<\mathrm{X}<(\overline{\mathrm{X}}+0,5 \mathrm{DS})$ & Cukup baik \\
4 & $(\overline{\mathrm{X}}-1,5 \mathrm{DS})<\mathrm{X}<(\overline{\mathrm{X}}-0,5 \mathrm{DS})$ & Kurang baik \\
5 & $\mathrm{X}<(\overline{\mathrm{X}}-1,5 \mathrm{DS})$ & Tidak baik \\
\hline
\end{tabular}

Sumber: Wiyono dan Sunarni (2009)

Tabel 2 Indeks Prestasi Mahasiswa Fungsionaris UKM KSR PMI Unit Universitas Negeri Malang

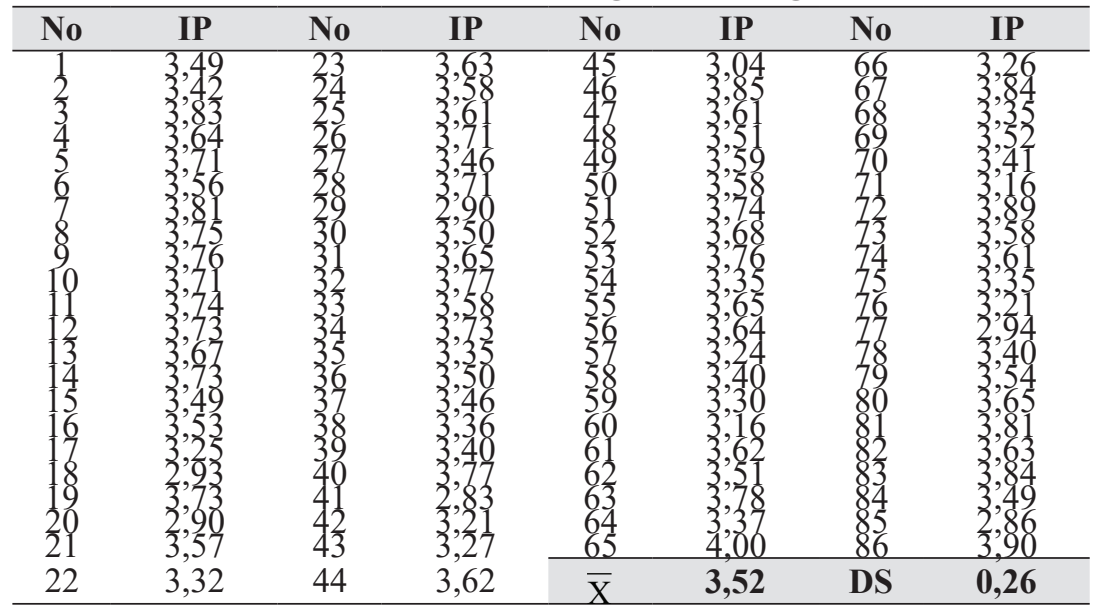

Tabel 3 Deskripsi Frekuensi Indeks Prestasi Mahasiswa Fungsionaris UKM KSR PMI Unit Universitas Negeri Malang

\begin{tabular}{|c|c|c|c|c|}
\hline No & Interval & $\mathbf{F}$ & $\%$ & Kategori \\
\hline $\begin{array}{l}1 \\
2 \\
3 \\
4 \\
5\end{array}$ & 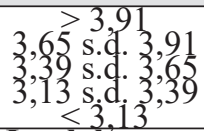 & $\begin{array}{l}29 \\
33 \\
16 \\
7\end{array}$ & $\begin{array}{l}1,16 \\
33,72 \\
38,37 \\
18,60 \\
8,14\end{array}$ & $\begin{array}{l}\text { Sangat baik } \\
\text { Baik } \\
\text { Cukup baik } \\
\text { Kurang baak } \\
\text { Tidak baik }\end{array}$ \\
\hline
\end{tabular}

han, Keindahan, dan Ketertiban Lingkungan; Juara Harapan 1 Kategori Lomba Menjalin Kerjasama; dan Juara Harapan 1 Kategori Lomba Tertib Administrasi dan Keuangan.

\section{PEMBAHASAN}

Jika mengacu pada Katalog Universitas Negeri Malang (UM) Edisi 2016, maka UKM KSR PMI Unit Universitas Negeri Malang merupakan ormawa yang kegiatan program pengembangan kemahasiswaannya termasuk dalam kelompok bakat, minat, dan kemampuan (Universitas Negeri Malang, 2016). Hasil penelitian ini selaras dengan penelitian Meinarta, dkk., (2014) yang menyimpulkan rata-rata nilai prestasi belajar mahasiswa yang aktif dalam organisasi kemahasiswaan tergolong dalam kategori sangat baik. Keaktifan mahasiswa dalam kegiatan ormawa memiliki manfaat dalam penguatan kemampuan berpikir, kemampuan komunikasi, kemampuan interpersonal, dan kepercayaan diri (Huang dan Chang, 2004). Gaya belajar seorang aktivis atau fungsionaris ormawa adalah gaya belajar sosial, sebab mereka selalu bertukar pikiran mengenai materi kuliah dan tugas yang diberikan oleh dosen (Putra, 2016).

Hal krusial yang dapat dipetik dari keaktifan mahasiswa dalam kegiatan ormawa adalah belajar mengorganisasikan kegiatan, belajar memimpin, belajar dipimpin, dan belajar berkomunikasi, seperti menyampaikan pendapat, mempertahankan gagasan, atau bernegosiasi. Jiwa sosial mahasiswa akan tumbuh seiring dengan banyaknya tipe orang yang ia kenal. Semakin tinggi pengalaman berorganisasi seseorang, selaras pula dengan sikap toleransinya kepada orang lain, sekalipun kepada orang sangat berbeda dari dirinya. Junaidi (2010) ber- 
dasarkan penelitiannya menyimpulkan bahwa mahasiswa dengan bergabung di ormawa, ia memiliki akses untuk berhubungan dengan banyak orang, karena dalam ormawa lazim menjalin kerjasama lintas kampus bahkan daerah. Selain itu kemampuan berpikir mahasiswa aktivis dalam menyelesaikan masalah organisasinya berpengaruh terhadap kemampuan berpikir dalam kuliahnya. Hal ini ditegaskan oleh Widayanto (2012) berdasarkan hasil penelitiannya menyimpulkan bahwa karakteristik prestasi para mahasiswa aktivis menunjukkan bahwa mahasiswa aktivis mempunyai prestasi yang baik.

Penelitian Budianto, dkk., (2014) menyimpulkan ada hubungan aktivitas mahasiswa dalam berorganisasi dengan prestasi belajar (indeks prestasi). Apiwie (2013) menegaskan bahwa mahasiswa aktivis dengan sering melihat fenomena yang terjadi di masyarakat, tentang masalah-masalah yang terjadi di kampus maupun luar kampus, dengan berbagai macam pendapat yang pro dan kontra, ia secara sadar akan terus berpikir untuk mencari solusi guna menyelesaikan masalah tersebut, dan hal itu tak jarang terbawa sampai dalam kelas, sehingga keikutsertaan mahasiswa dalam ormawa membawa dampak baik, khususnya peningkatan rasa percaya diri dan kemampuan membagi waktu mahasiswa. Mahasiswa aktivis dan fungsionaris akan selalu melakukan proses dealektika panjang sebagai kaum intelektual dan akan mewarnai perjalan perubahan bangsa menuju tatanan yang lebih baik (Taufik dan Affandi, 2014), dengan penuh tanggung jawab, komitmen, bermoral, dan beretika.

Partisipasi mahasiswa dalam ormawa akan meningkatkan kemampuan komunikasi yang baik dan lancar dengan orang lain, serta saling menghargai dan menghormati saat berkomunikasi, akan memaksimalkan prestasi belajar mahasiswa (Syofyan, 2013). Arahan dari dosen kepada semua mahasiswa menjadi hal yang krusial dalam meningkatkan kompetensi mahasiswa. Advisors are crucial in supporting the activities of student organizations and in encouraging and facilitating the holistic development of students (Light, 2017). Bergabung dalam ormawa merupakan pilihan pribadi mahasiswa, namun menjadi kewajiban perguruan tinggi untuk mempengaruhi para mahasiswa agar aktif dalam kegiatan ormawa, sebab mengem- bangkan perguruan tinggi harus ada sinergi antara pengembangan dosen dan mahasiswa. Hal ini menjadi penting, karena salah aspek penilaian kualitas perguruan tinggi adalah kualitas kegiatan kemahasiswaan (Kemristekdikti, 2015). Berbagai kelompok bidang ormawa, yaitu minat penalaran; minat kesenian; minat olah raga; minat khusus; bidang kesejahteraan; dan bidang kerohanian menjadi muara prestasi mahasiswa.

\section{SIMPULAN}

Berdasarkan hasil analisis data disimpulkan rerata indeks prestasi mahasiswa fungsionaris UKM KSR PMI Unit Universitas Negeri Malang sebesar 3,52 termasuk dalam predikat Dengan Pujian. Pengalaman yang diperoleh mahasiswa dalam kegiatan ormawa adalah belajar mengorganisasikan kegiatan, belajar memimpin, belajar dipimpin, dan belajar berkomunikasi, seperti menyampaikan pendapat, mempertahankan gagasan, atau bernegosiasi.

\section{DAFTAR RUJUKAN}

Apiwie, P. W. 2013. Perbedaan Prestasi Belajar antara Mahasiswa Jurusan Sejarah Fakultas Ilmu Sosial Universitas Negeri Semarang Angkatan 2008 yang Aktif dan tidak Aktif dalam Organisasi Kemahasiswaan. Indonesian Journal of History Education, 2(5), 34-39.

Badan Pengembangan dan Pembinaan Bahasa. 2017. Apa yang Dimaksud dengan Kata Aktivis? (Online), (http://badanbahasa. kemdikbud.go.id/lamanbahasa/petunjuk praktis/182), diakses 2 Januari 2017.

Budianto, J., Rizal, Y., dan Nurdin. 2014. Pengaruh Aktivitas Mahasiswa dalam Berorganisasi dan Disiplin Belajar terhadap Prestasi Belajar (IP). Jurnal Edukasi Ekobis, 12(2), 1-9.

Caesari, Y. K., Listiara, A., dan Ariati, J. 2013. Kuliah Versus Organisasi: Studi Kasus Mengenai Strategi Belajar pada Mahasiswa yang Aktif dalam Organisasi Mahasiswa Pecinta Alam Universitas Diponegoro. Jurnal Psikologi Undip, 12(2), 164-175.

Dictionary Cambridge. 2017. Meaning of "Functionary" in the English Dictionary, (Online), (http://dictionary.cambridge.org/ 
dictionary/english/functionary), diakses 2 Januari 2017.

Fry, H., Ketteridge, S., dan Marshall, S. 2009. A Handbook for Teaching and Learning in Higher Education: Enhancing Academic Practice. New York: Routledge.

Gunawan, I. 2009. Harapan untuk Rektor Baru Unlam. Banjarmasin Pos, 14 Mei, hlm. 6.

Gunawan, I. 2016. Pengantar Statistika Inferensial. Jakarta: Rajawali Pers.

Haryono, E., Akhdinirwanto, W., dan Ashari. 2013. Pengaruh Keaktifan Berorganisasi dan Konsep Diri tehadap Indeks Prestasi Mahasiswa Program Studi Pendidikan Fisika Universitas Muhammadiyah Purworejo Tahun Akdemik 2013/2014. Jurnal Radiasi, 4(1), 77-80.

Huang, Y., dan Chang, S. 2004. Academic and Cocurricular Involvement: Their Relationship and Best Combinations for Student Growth. Journal of College Student Development, 45(4), 391-406.

Junaidi, M. 2010. Hubungan antara Manajemen Diri dengan Prokrastinasi Akademik pada Mahasiswa Aktivis BEM di Lingkungan IAIN Sunan Ampel Surabaya. Tesis tidak diterbitkan. Surabaya: IAIN Sunan Ampel Surabaya.

Kartika, R. A. 2016. Konstruksi Sosial Siswa terhadap Prestasi Nonakademik: Studi pada Siswa Berprestasi di SMA Negeri 5 Surabaya, (Online), (http://journal.unair.ac.id/ download-fullpapers-kmntsab6b5bc60efull. pdf), diakses 2 Desember 2016.

Kemristekdikti. 2015. Klasifikasi dan Pemeringkatan Perguruan Tinggi - 2015, (Online),(https://ristekdikti.go.id/wp-content/ uploads/2016/03/paparanKPPT2015-1. pdf), diakses 2 Desember 2016.

Light, R. J. 2017. Advising A Student Organization. Boise: Boise State University.

Meinarta, I. W. O., Tripalupi, L. E., dan Suwena, K. R. 2014. Studi Komparatif Prestasi Belajar Mahasiswa yang Aktif dan tidak Aktif dalam Organisasi Kemahasiswaan FEB UNDIKSHA. Jurnal Jurusan Pendidikan Ekonomi, 4(1), 1-12.
Merriam Webster. 2017. Definition of Functionary, (Online), (https://www.merriam-webster. com/dictionary/functionary), diakses 3 Januari 2017.

Mulyono. 2008. Manajemen Admistrasi dan Organisasi Pendidikan. Jogjakara: Ar-Ruzz Media.

Oxford Dictionaries. 2017a. Activist, (Online), (https://en.oxforddictionaries.com/definition/ activist), diakses 3 Januari 2017.

Oxford Dictionaries. 2017b. Organizer, (Online), (https://en.oxforddictionaries.com/definition/ organizer), diakses 3 Januari 2017.

Pedoman Akademik Universitas Negeri Malang. 2015. Peraturan Rektor Universitas Negeri Malang Nomor 17 Tahun 2015 tentang Pedoman Pendidikan Universitas Negeri Malang Tahun Akademik 2015/2016. Malang: Biro Akademik, Kemahasiswaan, Perencanaan, Informasi, dan Kerja Sama; Universitas Negeri Malang.

Pusat Bahasa. 2008. Kamus Bahasa Indonesia. Jakarta: Pusat Bahasa Departemen Pendidikan Nasional.

Putra, H. G. I. 2016. Perilaku Belajar Mahasiswa Akuntansi: Aktivis, Hedonis, dan Study Oriented, (Online), (http://www. jimfeb.ub.ac.id/index.php/jimfeb/article/ viewFile/599/542), diakses 21 Desember 2016.

Sule, M. 2016. Pengaruh Aktifitas Organisasi Intrakampus terhadap Prestasi Belajar Mahasiswa Program Studi Geografi, (Online), (http://eprints.ung. ac.id/10542/1/2014-2-1-87202-451410041abstraksi-07012015022813.pdf), diakses 21 Desember 2016.

Syofyan, R. 2013. Pengaruh Sosial Ekonomi Keluarga, Partisipasi dalam Organisasi Kemahasiswaan, dan Komunikasi Interpersonal dengan Dosen terhadap Prestasi Belajar Mahasiswa PSPE. Jurnal Pendidikan Ekonomi, 21(2), 1-8.

Taufik, M., dan Affandi, M. A. 2014. Resistensi Gerakan Mahasiswa terhadap Kapitalisasi Pendidikan (Studi Organisasi Eksternal Kampus di Unesa). Paradigma, 2(3), 1-13. 
Triana, E. 2011. Pengaruh Keaktifan Berorganisasi dan Kebiasaan Belajar terhadap Prestasi Belajar Mahasiswa Jurusan Pendidikan Geografi Angkatan 2008 dan 2009 Universitas Negeri Yogyakarta. Tesis tidak diterbitkan. Yogyakarta: Universitas Negeri Yogyakarta.

Undang-undang Nomor 12 Tahun 2012 tentang Pendidikan Tinggi. 2013. Jakarta: Sinar Grafika.

Universitas Negeri Malang. 2016. Katalog Universitas Negeri Malang (UM) Edisi 2016. Malang: Biro Akademik, Kemahasiswaan, Perencanaan, Informasi, dan Kerja Sama; Universitas Negeri Malang.
Widayanto, A. 2012. Karakteristik Prestasi Akademik Mahasiswa Aktivis Organisasi Intrakampus di Fakultas Ilmu Sosial dan Ekonomi Universitas Negeri Yogyakarta. Tesis tidak diterbitkan. Yogyakarta: Universitas Negeri Yogyakarta.

Wiyono, B. B., dan Sunarni. 2009. Evaluasi Program Pendidikan dan Pembelajaran. Malang: Fakultas Ilmu Pendidikan Universitas Negeri Malang. 